\title{
Favorite Music Mediates Pain-related Responses in the Anterior Cingulate Cortex and Skin Pain Thresholds
}

This article was published in the following Dove Press journal: Journal of Pain Research

\author{
Iulia Antioch' \\ Tsumugu Furuta ${ }^{2}$ \\ Ryutaro Uchikawa ${ }^{3}$ \\ Masayo Okumura ${ }^{4}$ \\ Junichi Otogoto ${ }^{2}$ \\ Eiji Kondo ${ }^{4}$ \\ Norio Sogawa ${ }^{5}$ \\ Alin Ciobical \\ Mihoko Tomida ${ }^{2}$ \\ 'Department of Research, Faculty of \\ Biology, "Alexandru loan Cuza" \\ University of lasi, lasi, Romania; \\ ${ }^{2}$ Department of Oral Health Promotion, \\ Graduate School of Oral Medicine, \\ Matsumoto Dental University, Nagano, \\ Japan; ${ }^{3}$ Department of Dental \\ Conservation, Matsumoto Dental \\ University, Nagano, Japan; ${ }^{4}$ Department \\ of Oral Anatomy, Matsumoto Dental \\ University, Nagano, Japan; ${ }^{5}$ Department \\ of Dental Pharmacology, Matsumoto \\ Dental University, Nagano, Japan
}

Correspondence: Mihoko Tomida Department of Oral Health Promotion, Graduate School of Oral Medicine, Matsumoto Dental University, I780 Gobara Hirooka, Shiojiri-Shi, Nagano 399-078I, Japan

Tel +8I-263-5I-2208

Email mihoko.tomida@mdu.ac.jp
Purpose: Music therapy is widely used to enhance well-being, reduce pain, and distract patients from unpleasant symptoms in the clinical setting. However, the degree to which music modulates pain perception is unknown. The medial pain pathway including the limbic system is associated with emotion, but how music alters pathway activity is unclear. The aim of the study was to investigate pain thresholds and pain-related responses in the anterior cingulate cortex (ACC) and whether they were modulated when subjects listened to their favorite music genre.

Subjects and Methods: First, 30 subjects were examined for left forearm pain threshold using electrical stimulation with Pain Vision PS-2011N. The pain thresholds with and without music were compared. Second, when an $80-\mu \mathrm{A}$ current from Pain Vision was applied to the left ankle of eight women, the pain-related responses of the ACC with and without music were observed with functional magnetic resonance device (fMRI). The changes in the painrelated activity in both parameters were discussed.

Results: The median pain threshold with favorite music was $38.9 \mu \mathrm{A}$, compared to $29.0 \mu \mathrm{A}$ without, which was significantly different $(p<0.0001)$. The men's thresholds were significantly higher than women's both with music $(p<0.05)$ and without music $(p<0.01)$. The pain threshold in women was more strongly affected by music than in men. The fMRI results showed that the pain-related response in the ACC in five of eight subjects was attenuated while they listened to their favorite music. No change was observed in the other three subjects.

Conclusion: The present findings suggest that pain perception might be strongly affected by listening to favorite music, possibly through modulation of pain-related responses in the ACC.

Keywords: pain threshold, music, forearm, anterior cingulate cortex, medial pathway

\section{Introduction}

Pain is a very important signal to warn of actual or potential tissue damage. However, it is also unpleasant and intrusive, which might inhibit physical activity or lead to depression. The pain eventually enhances disease-associated psychological and physiological deterioration, ${ }^{1}$ and these mental and physical changes impair quality of life. ${ }^{2}$

Many studies have demonstrated that the cognitive degree of pain is appreciably influenced by environment or emotion. For example, palatable food, pleasant odors, and interesting things were all found to reduce pain perception. ${ }^{3}$ As a pleasant stimuli, music therapy could be considered as a nonpharmacological method for reducing 
patient pain and anxiety. ${ }^{4-6}$ Music effectively improves mood because it elicits a comfortable feeling with sound, rhythm, and melody, ${ }^{7-9}$ calming the mind through the autonomic nervous system. ${ }^{10,11}$

Listening to music affects brain regions related with emotion such as the amygdala and anterior cingulate cortex (ACC), and the positive emotion interferes with nociceptive processing at the level of the spinal cord. ${ }^{12}$ A previous report stated that the awareness of pain cognition was affected by pleasant or unpleasant stimulation; that is, pleasant music reduced pain, whereas unpleasant stimuli had no effects or tended to increase pain. ${ }^{13}$ However, the degree to which pain perception is modulated by emotion remains poorly understood. ${ }^{14-16}$

There are three ascending pain pathways: lateral, medial, and spinohypothalamic. The lateral pathway projects to the primary somatosensory area (S1) and secondary somatosensory area (S2) of the cerebral cortex via the lateral nucleus thalamus from the spinal cord, ${ }^{17}$ which contributes to the strength of pain felt. The medial pain pathway projects to the limbic system including the ACC and insula via the medial nucleus thalamus from the spinal cord and is associated with the affective-motivational component of pain (emotional reactions, attention to the pain stimulation, and escape response). ${ }^{18,19}$ The ACC is well known to participate in pain sensation and nociceptive processing in animals and humans. $^{20-22}$ The spinohypothalamic pathway activates the autonomic nervous system and endocrine system in response to pain. We hypothesized that favorite music would reduce pain-related response on medial pain pathway.

Functional magnetic resonance imaging (fMRI) has been used to assess activity of brain structures during neural processing of acute pain. ${ }^{23}$ Moreover, the imaging changes induced by sensory or motor activation depend on the task during imaging. The most commonly measured signal is blood oxygen level-dependent contrast (BOLD), which expresses neuronal activity as the variation in oxy hemoglobin $(\mathrm{Hb})$ to deoxy $\mathrm{Hb}$ ratio.

In this study, we investigated how listening to favorite music affected the change in pain threshold and the painrelated response of ACC to clarify the modulatory effect of music and emotion.

\section{Subjects and Methods Subjects}

Thirty volunteers (15 men, 15 women, 13-85 years old) participated in the pain threshold study. The mean $\pm \mathrm{SE}$ age of men was $45.4 \pm 1.3$ years and women was $50.0 \pm 1.2$ years. They did not have a history of cardiovascular disease, neurological disorders, and diabetes and did not take psychotropic and analgesic medication. Among them, eight women (29-51 years old) took part in the fMRI study of the pain-related response in the ACC.

The present study was approved by the Ethics Committee of Matsumoto Dental University (No. 145 and 195). Informed consent was obtained from all participants. This study followed the Declaration of Helsinki with regard to medical protocol and ethics.

\section{Music}

Each subject brought their own favorite CD. In both experiments (forearm pain threshold and fMRI of the ACC), subjects were listening to the same music.

\section{Pain Threshold Assessment}

Pain thresholds were measured using Pain Vision PS2011N (Nipro Co., Ltd.). A disposable skin electrode (ELBAND, Nipro Co., Ltd.) was pasted on the left forearm to deliver electrical stimulation (pulse electric current: $0.3 \mathrm{~ms}$, $50 \mathrm{~Hz}$ ). The intensity of the stimulation was gradually increased. When subjects recognized pain on the forearm, they used a hand switch to stop the electrical stimulation, and the stopped electrical intensity was considered the pain threshold. We compared thresholds with and without favorite music and between genders.

\section{Procedure}

This study was performed in a silent room maintained at $23^{\circ} \mathrm{C}$. The participants sat in a comfortable chair, wore headphones, and kept their eyes open.

All subjects rested for $5 \mathrm{~min}$, and forearm pain threshold without music was measured three times with 1-min intervals. After a 2-minute rest, forearm pain threshold was measured using the same protocol while subjects listened to their favorite music (Figure 1).

The subject-selected music started to play $10 \mathrm{~s}$ before the initial electric stimulation, and it continued until the completion of the third measurement (Figure 1).

\section{Statistical Analysis of Pain Threshold}

We used Wilcoxon tests to compare forearm pain thresholds with and without music. Mann-Whitney tests were performed to compare findings in men and women. All statistical analyses were processed using SPSS ver.23 (IBM), and difference were considered significant at $p<0.05$. 


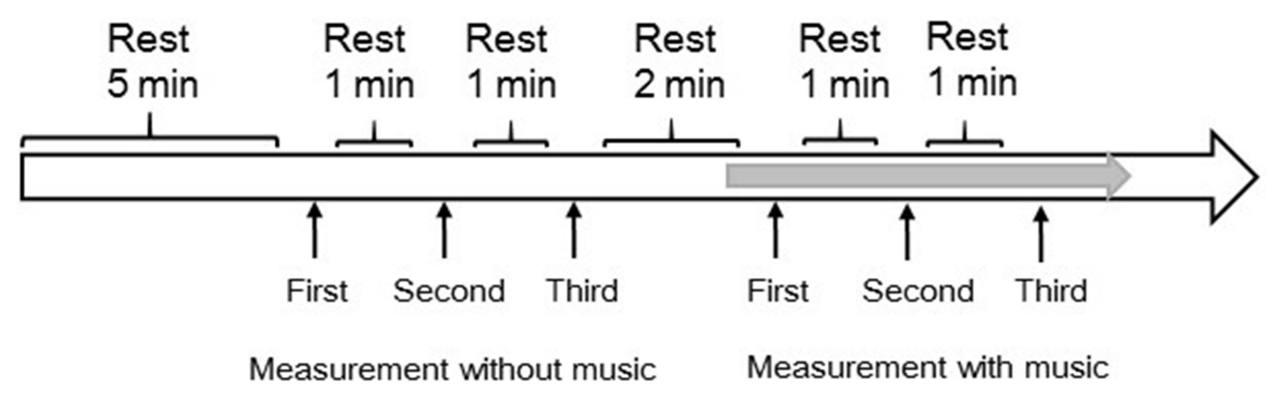

\section{: favorite music}

Figure I Assessment of forearm pain threshold. Measurements of each condition (music or no music) were performed three times with I-minute rest intervals.

\section{fMRI}

\section{Task Design}

Before beginning the experiment, we performed pre-tests to determine the optimal intensity of electrical stimulation generated by Pain Vision for ankle stimulation. The individual difference of pain threshold for eight subjects was not almost recognized in MRI room, which results from very loud sound from MRI machine. Then, we fixed the intensity of pain stimulation with $80 \mu \mathrm{A}$. The current was painful in all subjects but did not elicit stress due to the intermittent stimulation.

The task design was composed of four cycles without music and four cycles with music. One cycle comprised an On and Off time that were each $32 \mathrm{~s}$ (Figure 2A). A disposable electrode was attached on the inside of the left ankle of each subject who put on headphones made of resin. The $80-\mu \mathrm{A}$ current was applied to the left ankle for 4 $\mathrm{s}$ with 4-s rest intervals in the On time (Figure 2B). The music started to play at the fifth cycle and continued to play until the end of the eight cycles (Figure 2A).

\section{Image Acquisition}

ACC activity was investigated using a Signa MR/i Echo Speed 1.5T (GE Healthcare) at the Ibi public welfare hospital. The BOLD parameters were as follows: repetition time $=4000 \mathrm{~ms}$, echo time $=44 \mathrm{~ms}$, flip angle $=90$, field of view $=240 \mathrm{~mm}, \quad$ matrix $=64 \quad \mathrm{X} \quad 64$, Slice thickness $=3.8 \mathrm{~mm}$.

\section{Data Analysis}

All images were analyzed using SPM5 (Wellcome Centre for Human Neuroimaging) and MATLAB 6.5.2. (MathWorks). At first, the movement gap of the head and the time lag during photography for all functional images were corrected. Next, each personal brain in the image was converted into standard brain to normalize anatomically. Finally, we compared ACC activity from the images in Off and On time with brain template provided by Montreal Neurological Institute ${ }^{24}$ and Talairach's atlas. ${ }^{25}$

\section{Results}

\section{Music Selection}

The kinds of the music that subjects chose were classical music ( 2 women), Japanese pop with song (4 men and 3 women), Chinese pop without song ( 2 men), Japanese ballads with song ( 5 men and 7 women), rock with English song (1 man and 1 woman) and Japanese folk with song ( 3 men and 2 women).

Eight subjects who selected healing classical music $(n=1)$, Japanese pop $(n=2)$, Japanese ballads $(n=4)$ and rock $(n=1)$ participated in fMRI study.

\section{Pain Thresholds}

The median pain threshold with music in the all subjects was $38.9 \mu \mathrm{A}$, while that without music was 29.0 $\mu \mathrm{A}$. Pain thresholds with music were significantly higher than those without music $(p<0.0001$, Figure 3$)$. The median of men's pain thresholds with music was $42.6 \mu \mathrm{A}$, compared to $40.3 \mu \mathrm{A}$ without $(p<0.05)$. The women's median pain thresholds with and without music were $28.3 \mu \mathrm{A}$ and $18.5 \mu \mathrm{A}$, respectively $(p<0.0001$, Figure 4). Men's pain thresholds were significantly higher than women both with music $(p<0.05)$ and without music $(p<0.01)$ (Figure 4).

\section{fMRI}

ACC activity during electrical stimulation on the ankle was observed in all eight women who participated in 
A

\section{Favorite music}
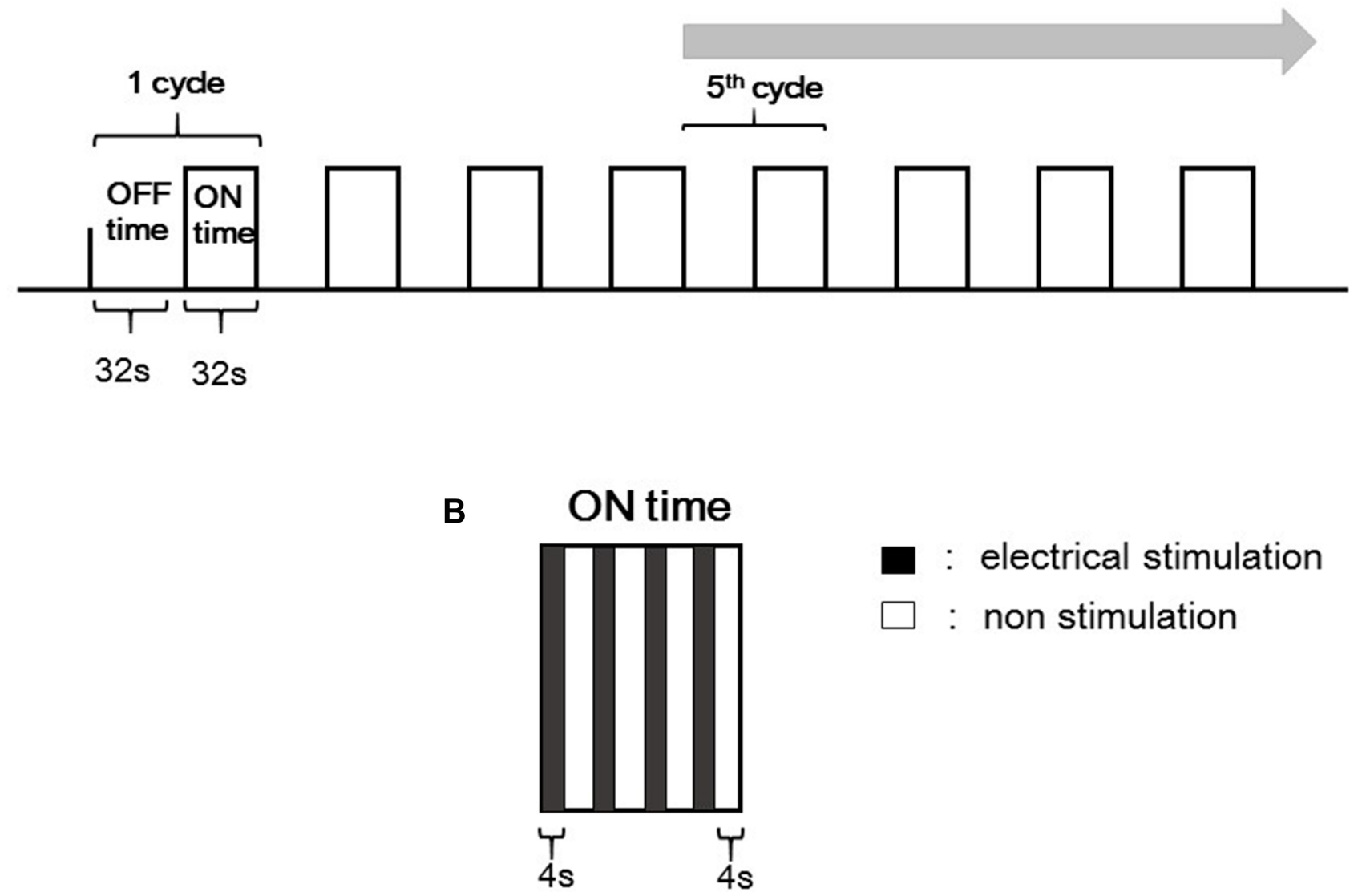

\section{$\square$ : electrical stimulation \\ : non stimulation}

Figure 2 Task design of the fMRI study. (A) The task was composed of four cycles without music and four cycles of listening to the subject's favorite music. One cycle was comprised of On time (32 s of current) and Off time (32 s of no current). (B) Electrical stimulation at the On time. An 80- $\mu \mathrm{A}$ electrical current was applied to the left ankle for $4 \mathrm{~s}$ four times during On time.

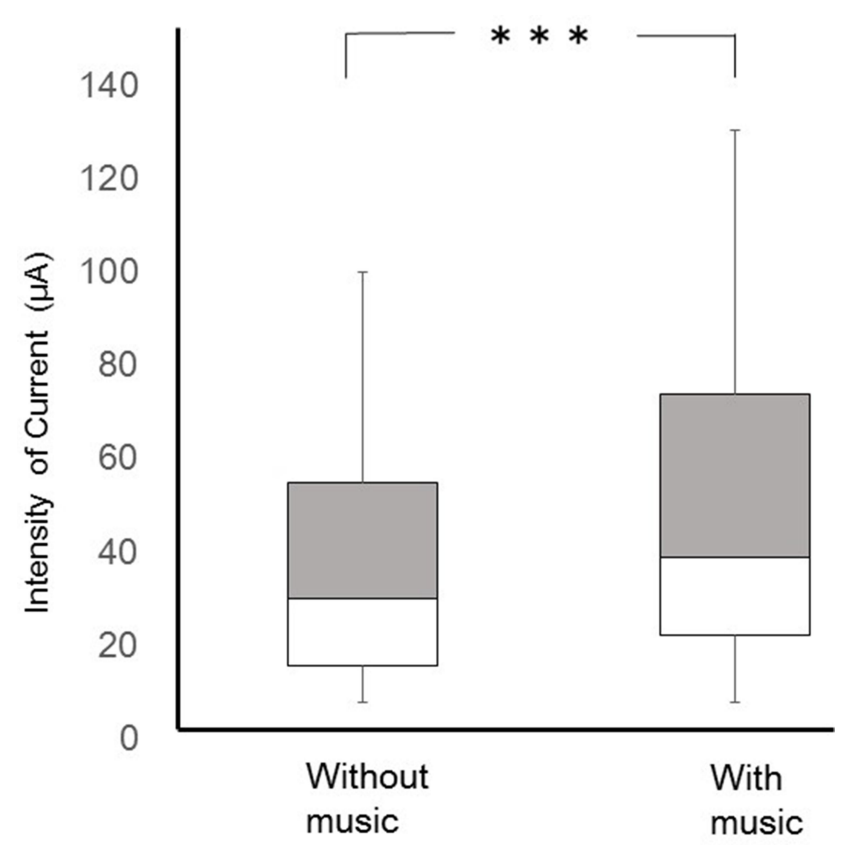

Figure 3 Forearm pain threshold comparison with and without favorite music. $*_{* *} p<0.0001$ (Wilcoxon test). this experiment (Figure 5A and B). The location of the most significant active focus for ACC was showed at $-10,12,26(\mathrm{x}, \mathrm{y}, \mathrm{z})$ as an anatomical region given in the Talairach coordinates. ${ }^{25}$ In five subjects, the painrelated response in the ACC was attenuated by listening to their favorite music (Figure $5 \mathrm{C}$ and $\mathrm{D}$ ). In three subjects who selected classical music $(\mathrm{n}=1)$ and ballads $(\mathrm{n}=2)$, there was no discernible change in ACC activity with and without music.

\section{Discussion}

Pain recognition is determined by the balance between peripheral and central influences and is influenced by memories and emotional, pathological, genetic, and cognitive factors. ${ }^{26}$ This makes it is difficult to assess pain strength in individuals. The Pain Vision system used in this study can objectively quantity pain threshold using electrical stimulation and a safety device used in medical clinical practice. 


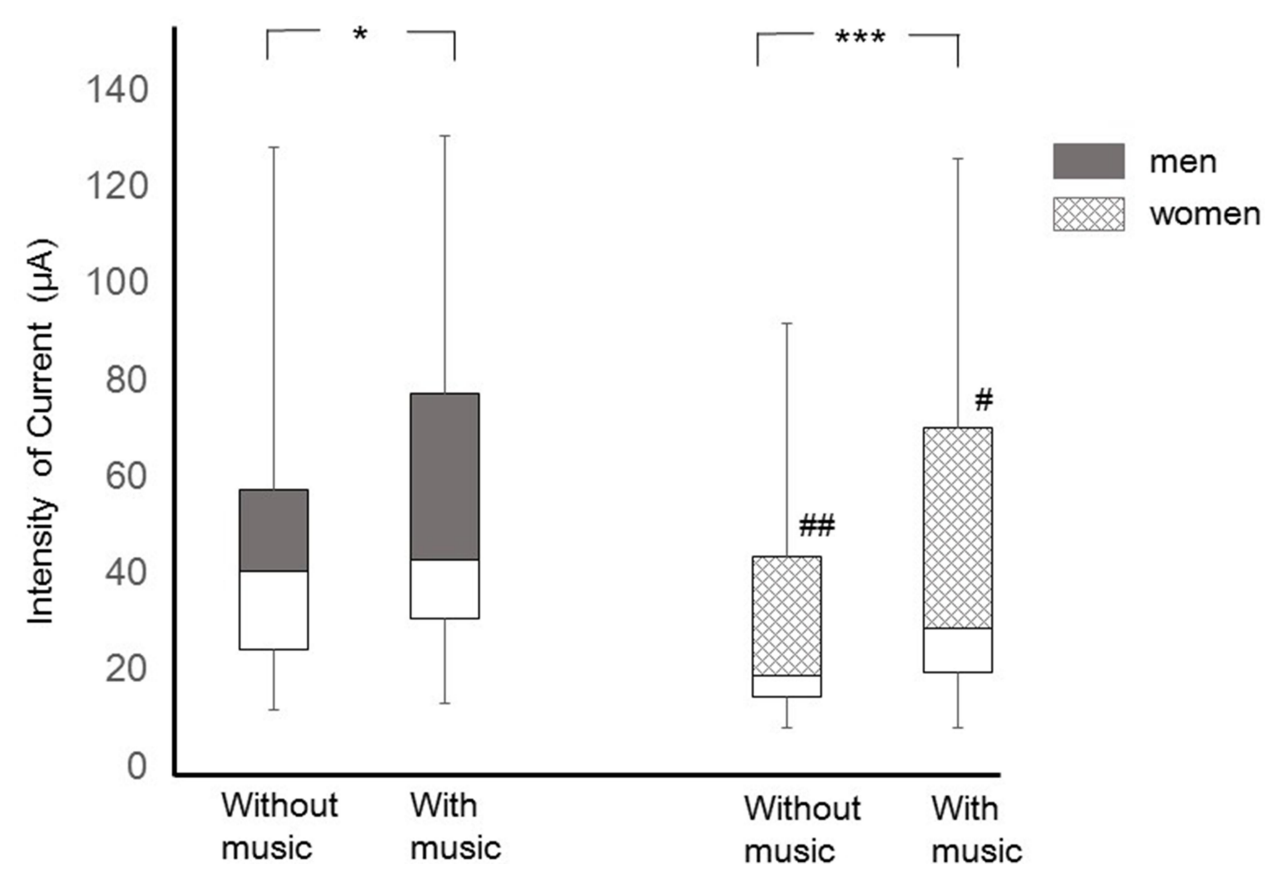

Figure 4 Forearm pain threshold with and without music stratified by gender. $*$ Threshold comparison with favorite music versus without music: $* p<0.05$, $* * * p<0.000$ I (Wilcoxon test); ${ }^{\#}$ Gender comparison with favorite music or without music: ${ }^{\#} p<0.05,{ }^{\#} p<0.01$ (Mann-Whitney test).

In this study, the value of the forearm pain threshold while listening to music was significantly higher than that without music. Our results demonstrate the subject's favorite music could increase their pain threshold; that is, the music decreased sensitivity. Pain is also enhanced by painrelevant anxiety. ${ }^{27}$ However, some questionnaire-based studies found that listening to music reduced anxiety and stress as well as pain. ${ }^{28-30}$ It is thought that music performance (tempo, rhythm, and song) could enhance positive emotion, which helps relieve pain, anxiety, unpleasant and stress. ${ }^{31}$ Classical music is widely used in dental or medical clinics to enhance relaxation induced by physiologic and psychological responses to the music. ${ }^{32-34}$ We previously compared pain threshold on the skin and gingiva while subjects listened to classical music, pop, or no music. The thresholds on the skin and gingiva were significantly higher during pop music compared to no music. For the oral cavity gingiva, classical music also increased the threshold. ${ }^{35}$ When the value of the pain threshold without music was set as $100 \%$, the change rate of the pain threshold with pop music was $120.9 \% .{ }^{35}$ In this study, the change rate with favorite music was even higher, at $125.3 \%$. This demonstrates that an individual's favorite music can appreciably reduce acute pain. This result was consistent with our hypothesis. However, in previous study using autoalgometry, no significant effect on pain threshold was obtained with Mozart's music compared to silent. ${ }^{36}$ It was suggested that used device and evaluation method might result in the difference. There was certainly the individual difference of the pain perception in the even comfortable environment, but we obtained an effective result with listening to favorite music.

The human body descending pain modulation system resides in the periaqueductal gray (PAG) of the brainstem as the restraint system for the pain. ${ }^{37}$ Music affects the generation of morphine-6-glucuronide, expression of the $\mu$ opioid receptor, ${ }^{38}$ and promotes endorphin production. ${ }^{39}$ The descending pain-modulatory mechanism attenuates ascending signals through opioidergic, noradrenergic, and serotonergic signaling via the rostral ventromedial medulla or locus ceruleus. ${ }^{13,40}$ These functions might underlie the music-mediated increase in pain threshold. That is, pain perception contributes to the balance between ascending and descending pathways with emotional effects.

Thresholds in men were significantly higher than women both with music and without music. One gender difference that could explain this observation is the more prominent effect of the serotonin/dopamine system on pain processing in men. ${ }^{41}$ Therefore, men's pain thresholds were higher than women's. Gender differences are caused 


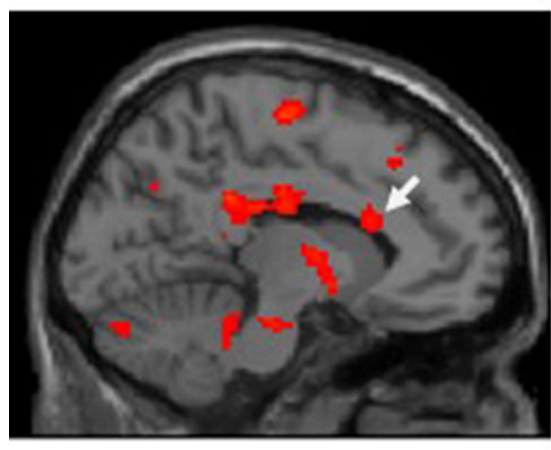

A

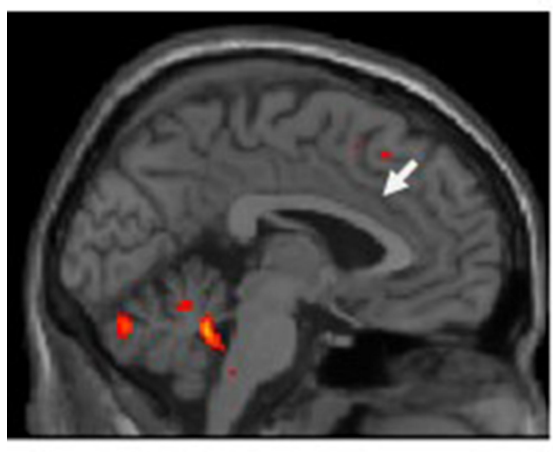

C

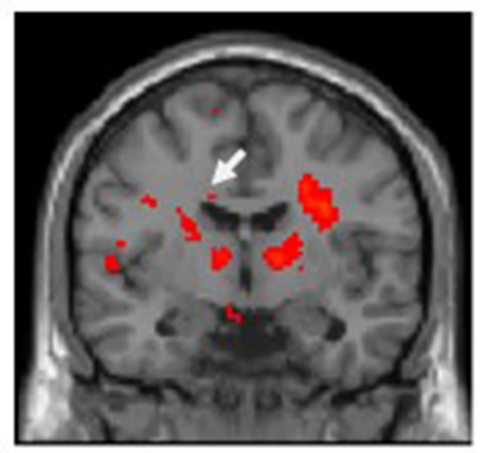

B

\section{$Z$ value}
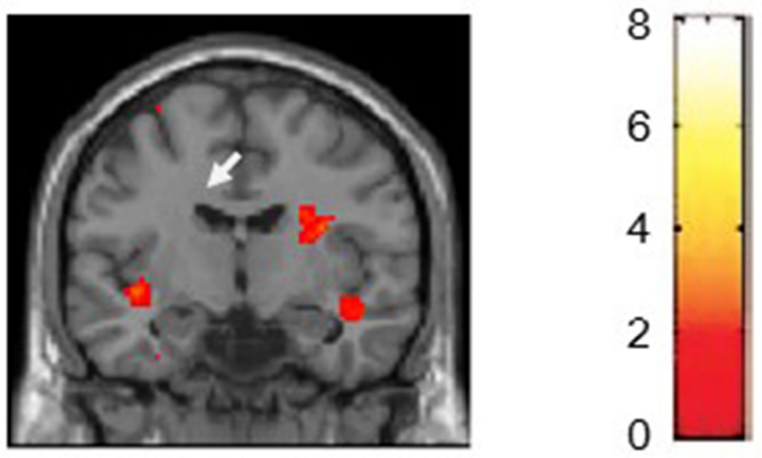

Figure 5 Brain regional activity by electrical stimulation on the ankle. Imaging of the pain-related response in the ACC (white arrow) with and without favorite music. $(P<0.05)$. (A) Sagittal image showing activation induced by pain without music. (B) Coronal image showing activation induced by pain without music. (C) Sagittal image showing activation induced by pain with music. (D) Coronal image showing activation induced by pain with music.

by interactions among the endogenous opioid system and genetic, physiological, gonadal hormonal, psychological, and social factors. ${ }^{42,43}$

Comparison of forearm pain thresholds between the music and no music condition, women had a more significant difference than men. There was not the significant difference between the age of men and women. Therefore, the gender difference may be that psychological and emotional factors contributed to greater pain relief in women. This would suggest that stimuli awareness in women is more easily affected by emotion compared with in men.

We identified an fMRI-based neurologic signature in the ACC associated with electrical pain stimulation, and this response was altered when subjects were listening to their favorite music. In five subjects, the ACC pain-related response to electrical ankle stimulation was attenuated by music. The medial pain pathway might be inhibited by comforting emotions elicited by one's favorite music. ${ }^{44}$
The ACC, insula, amygdala, and prefrontal cortex are important regions that process the affective-motivational dimension of the pain experience. ${ }^{45-47}$

There is another possible expectation for our findings. An attention effect (distraction from pain) could modulate neural activity in the pain matrix. ${ }^{48}$ Subjects were paying attention to the music even during electrical stimulation delivery. Researchers have investigated whether alterations in attention affect brainstem activity and nociceptive processing via these cortico-brainstem influences. A neurophysiology study showed that increased PAG activity significantly distracted attention from pain. ${ }^{49}$ Our results also suggested that listening to one's favorite music modulates pain-associated activity within the PAG and engage the descending inhibitory system. It was reported that meditation mainly attenuated the medial system of pain perception, including the ACC and insula. ${ }^{50}$ Five subjects showed reduced ACC responses while music was playing, suggesting that they were 
distracted from pain, similar to the above study using meditation. However, three subjects did not show changes in pain-related ACC activity between the silent and music conditions, even though their pain thresholds on the forearm were increased by favorite music. The narrow space and noisy sound of the MRI apparatus or painful ankle stimulation might have caused anxiety and stress, which inhibited the beneficial musical effects. The three subjects selected soft music such as classical music and still ballads, which suggested that rhythmical music with rapid tempo might be effective for pain in the small and noisy place.

There are several limitations in this study. First, although the pain threshold might vary according to age, the range in this study was wide. Second, we also did not decide the music category; rather, subjects were asked to bring their favorite $C D$, so the types varied. Third, the fMRI sample size was small and only included women because men were working in the daytime. Still, we hypothesize that there is a gender difference of pain-related brain activity. Moreover, although we focused on the ACC, it is thought that there are also parts of the brain where emotion can modulate painrelated responses. Further investigations are needed investigate changes in brain areas (orbitofrontal, insula, amygdala and auditory cortices) related with emotion and sound to clarify mechanisms underlying pain. ${ }^{51,52}$ However, our results suggest that the pain threshold and pain-related activity of the medial pain pathway are affected by music.

In summary, our results show that listening to favorite music increased forearm pain threshold and tended to attenuate the pain-related response in the ACC, suggesting the influence of a descending pain-modulatory mechanism with endorphin production induced by emotion.

\section{Conclusion}

Listening to favorite music effectively increased forearm pain thresholds. These results suggest that sensitivity to acute pain might decrease while hearing one's favorite music. The painrelated response in the ACC was also affected during favorite music listening. It is possible that the musical stimulus enhanced descending pain inhibition and reduced activity in ascending pain pathways. Music therapy to decrease pain sensibility during clinical procedures can be easily implemented as a low-cost therapy with no side effects.

\section{Abbreviations}

ACC, anterior cingulate cortex; BOLD, blood oxygen level-dependent; MRI, magnetic resonance imaging; $\mathrm{PAG}$, periaqueductal gray.

\section{Funding}

This work was supported by the National Science Foundation of Japan (No. 25463158). Alin Ciobica and Iulia Antioch were supported by a research grant for Young Teams offered by UEFISCDI Romania, no. PNIII-P1-1.1-TE-2016-1210, contract no. 58 from 02/05/ 2018, called "Complex Study Regarding the Interactions Between Oxidative Stress, Inflammation and Neurological Manifestations in the Pathophysiology of Irritable Bowel Syndrome (Animal Models and Human Patients)."

\section{Disclosure}

The authors report no conflicts of interest in this work.

\section{References}

1. Strang P. Cancer pain-a provoker of emotional, social and existential distress. Acta Oncol. 1998;37:641-644. doi:10.1080/ 028418698429973

2. Ferrell BR. The impact of pain on quality of life. A decade of research. Nurs Clin North Am. 1995;30:609-624.

3. Leknes S, Tracey I. A common neurobiology for pain and pleasure. Nat Rev Neurosci. 2008;9:314-320. doi:10.1038/nrn2333

4. McClean S, Bunt L, Daykin N. The healing and spiritual properties of music therapy at a cancer care center. J Altern Complement Med. 2012;18:402-407. doi:10.1089/acm.2010.0715

5. Krishnaswamy P, Nair S. Effect of music therapy on pain and anxiety levels of cancer patients: a pilot study. Indian J Palliat Care. 2016;22:307-311. doi:10.4103/0973-1075.185042

6. Cepeda MS, Carr DB, Lau J, et al. Music for pain relief. Cochrane Database Syst Rev. 2006;2:CD004843.

7. Kemper KJ, Danhauer SC. Music as therapy. South Med J. 2005;98:282-288. doi:10.1097/01.SMJ.0000154773.11986.39

8. Hilliard RE. The effects of music therapy on the quality and length of life of people diagnosed with terminal cancer. $J$ Music Ther. 2003;40:113-137. doi:10.1093/jmt/40.2.113

9. Gallagher LM. Developing and using a computerized database for music therapy in palliative care. J Palliat Care. 2001;17:147-154.

10. Kunikullaya KU, Goturu J, Muradi V, et al. Music versus lifestyle on the autonomic nervous system of prehypertensives and hypertensives-a randomized control trial. Complement Ther Med. 2015;23:733-740. doi:10.1016/j.ctim.2015.08.003

11. Do Amaral JA, Guida HL, de Abreu LC, et al. Effects of auditory stimulation with music of different intensities on heart period. J Tradit Complement Med. 2016;6:23-28. doi:10.1016/j.jtcme.2014.11.032

12. Sandrini G, Serrao M, Rossi P, et al. The lower limb flexion reflex in humans. Prog Neurobiol. 2005;77:353-395. doi:10.1016/j. pneurobio.2005.11.003

13. Roy M, Lebuis A, Hugueville L, et al. Spinal modulation of nociception by music. Eur J Pain. 2012;16:870-877. doi:10.1002/j.15322149.2011.00030.x

14. Kuner R, Flor H. Structural plasticity and reorganisation in chronic pain. Nat Rev Neurosci. 2017;18:113. doi:10.1038/nrn.2017.5

15. Shim JS, Chae JY, Kang SG, et al. Can listening to music decrease pain, anxiety, and stress during a urodynamic study? A randomized prospective trial focusing on gender differences. Random Control Trial. 2017;104:59-63.

16. Mak N, Reinders IMA, Slockers SA, et al. The effect of music in gynaecological office procedures on pain, anxiety and satisfaction: a randomized controlled trial. Gynecol Surg. 2017;14:14. doi:10.1186/s10397-017-1016-2 
17. Mills EP, Alshelh Z, Kosanovic D, et al. Alters brainstem pain-modulation circuitry connectivity during spontaneous pain intensity fluctuations. J Pain Res. 2020;13:2223-2235. doi:10.2147/ JPR.S252594

18. Salimpoor VN, Zald DH, Zatorre RJ, et al. Predictions and the brain: how musical sounds become rewarding. Trends Cogn Sci. 2015;19:86-91. doi:10.1016/j.tics.2014.12.001

19. Zatorre RJ. Musical pleasure and reward: mechanisms and dysfunction. Ann N Y Acad Sci. 2015;1337:202-211. doi:10.1111/ nyas. 12677

20. Bliss TV, Collingridge GL, Kaang BK, et al. Synaptic plasticity in the anterior cingulate cortex in acute and chronic pain. Nat Rev Neurosci. 2016;17:485-496. doi:10.1038/nrn.2016.68

21. Wager TD, Atlas LY, Lindquist MA, et al. An fMRI-based neurologic signature of physical pain. $N$ Engl J Med. 2013;368:1388-1397. doi:10.1056/NEJMoa1204471

22. Zhang R, Tomida M, Katayama Y, et al. Response durations encode nociceptive stimulus intensity in the rat medial prefrontal cortex. Neuroscience. 2004;125:777-785. doi:10.1016/j.neuroscience.2004.01.055

23. Apkarian AV, Bushnell MC, Treede RD, et al. Human brain mechanisms of pain perception and regulation in health and disease. Eur J Pain. 2005;9:463-484. doi:10.1016/j.ejpain.2004.11.001

24. Lutz K, Specht K, Shah NJ, et al. Tapping movements according to regular and irregular visual timing signals investigated with fMRI. Neuroreport. 2000;11:1301-1306. doi:10.1097/00001756200004270-00031

25. Talairach J, Tournoux P. Co-Planar Stereotaxic atlas of the Human Brain. New York: Thieme; 1988.

26. Tracey I, Mantyh PW. The cerebral signature for pain perception and its modulation. Neuron. 2007;55:377-391. doi:10.1016/j. neuron.2007.07.012

27. Ploghaus A, Narain C, Beckmann CF, et al. Exacerbation of pain by anxiety is associated with activity in a hippocampal network. $J$ Neurosci. 2001;21:9896-9903. doi:10.1523/JNEUROSCI.21-2409896.2001

28. Calcaterra V, Ostuni S, Bonomelli I, et al. Music benefits on postoperative distress and pain in pediatric day care surgery. Pediatr Rep. 2014;6:5534. doi:10.4081/pr.2014.5534

29. Kankkunen P, Vaajoki A. The effectiveness of music on postoperative pain among adults and children: the unused resource. Pain Manag. 2019;9:339-341. doi:10.2217/pmt-2018-0074

30. Linnemann A, Strahler J, Nater UM. The stress-reducing effect of music listening varies depending on the social context. Psychoneuroendocrinology. 2016;72:97-105. doi:10.1016/j. psyneuen.2016.06.003

31. Lu X, Thompson WF, Zhang L, et al. Music reduces pain unpleasantness: evidence from an EEG study. J Pain Res. 2019;13:3331-3342. doi: 10.2147/JPR.S212080

32. Yamashita K, Kibe T, Ohno S, et al. The effects of music listening during extraction of the impacted mandibular third molar on the autonomic nervous system and psychological state. J Oral Maxillofac Surg. 2019;77:1153.e1-1153.e8. doi:10.1016/j. joms.2019.02.028

33. Ozkalayci O, Araz C, Cehreli SB, et al. Effects of music on sedation depth and sedative use during pediatric dental procedures. $J$ Clin Anesth. 2016;34:647-653. doi:10.1016/j.jclinane.2016.07.001

34. Hole J, Hirsch M, Ball E, et al. Music as an aid for postoperative recovery in adults: a systematic review and meta-analysis. Lancet. 2015;386:165916-165971. doi:10.1016/S0140-6736(15)60169-6
35. Furuta T, Uchikawa R, Shikura O, et al. The effects of auditory stimulation with pleasant and unpleasant sound on the pain threshold of gingiva and skin. Oral Health Dent Sci. 2019;3:1-5.

36. Vecchione N, Lorusso L, Viggiano A. Mozart's or ambient music do not affect autoalgometric pain threshold. Transl Med UniSa. 2020;22:1-4.

37. Wiech K, Ploner M, Tracey I. Neurocognitive aspects of pain perception. Trends Cogn Sci. 2008;12:306-313. doi:10.1016/j. tics.2008.05.005

38. Stefano GB, Zhu W, Cadet P, et al. Music alters constitutively expressed opiate and cytokine processes in listeners. Med Sci Monit. 2004;10:MS18-27.

39. Dunbar RI, Kaskatis K, MacDonald I, et al. Performance of music elevates pain threshold and positive affect: implications for the evolutionary function of music. Evol Psychol. 2012;10:688-702. doi:10.1177/147470491201000403

40. Koh JC, Kong HJ, Kim MH, et al. Comparison of analgesic and adverse effects of oxycodone- and fentanyl-based patient-controlled analgesia in patients undergoing robot-assisted laparoscopic gastrectomy using a 55:1 potency ratio of oxycodone to fentanyl: a retrospective study. J Pain Res. 2020;13:2197-2204. doi:10.2147/ JPR.S264764

41. Watkins LR, Hutchinson MR, Johnston IN, et al. Glia: novel counter-regulators of opioid analgesia. Trends Neurosci. 2005;28:661-669. doi:10.1016/j.tins.2005.10.001

42. Pieretti S, Di Giannuario A, Di Giovannandrea R, et al. Gender differences in pain and its relief. Ann Ist Super Sanita. 2016;52:184-189.

43. Aloisi AM, Bachiocco V, Costantino A, et al. Cross-sex hormone administration changes pain in transsexual women and men. Pain. 2007;132(Suppl 1):S60-67. doi:10.1016/j.pain.2007.02.006

44. Buffington AL, Hanlon CA, McKeown MJ. Acute and persistent pain modulation of attention-related anterior cingulate fMRI activations. Pain. 2005;113:172-184. doi:10.1016/j.pain.2004.10.006

45. Orenius TI, Raij TT, Nuortimo A, et al. The interaction of emotion and pain in the insula and secondary somatosensory cortex. Neuroscience. 2017;349:185-194. doi:10.1016/j.neuroscience.2017.02.047

46. Nakata H, Sakamoto K, Kakigi R. Meditation reduces pain-related neural activity in the anterior cingulate cortex, insula, secondary somatosensory cortex, and thalamus. Front Psychol. 2014;5:1489. doi:10.3389/fpsyg.2014.01489

47. Dobek CE, Beynon ME, Bosma RL, et al. Music modulation of pain perception and pain-related activity in the brain, brain stem, and spinal cord: a functional magnetic resonance imaging study. J Pain. 2014;15:1057-1068. doi:10.1016/j.jpain.2014.07.006

48. Dumoulin S, Bouchard S, Loranger C, et al. Are cognitive load and focus of attention differentially involved in pain management: an experimental study using a cold pressor test and virtual reality. J Pain Res. 2020;13:2213-2222. doi:10.2147/JPR.S238766

49. Tracey I, Ploghaus A, Gati JS, et al. Imaging attentional modulation of pain in the periaqueductal gray in humans. $J$ Neurosci. 2002;22:2748-2752. doi:10.1523/JNEUROSCI.22-07-02748.2002

50. Zeidan F, Martucci KT, Kraft RA, et al. Brain mechanisms supporting the modulation of pain by mindfulness meditation. Version 2. J Neurosci. 2011;31:5540-5548. doi:10.1523/JNEUROSCI.5791-10.2011

51. Salimpoor VN, van den Bosch I, Kovacevic N, et al. Interactions between the nucleus accumbens and auditory cortices predict music reward value. Science. 2013;340:216-219. doi:10.1126/science.1231059

52. Koelsch S. Brain correlates of music-evoked emotions. Nat Rev Neurosci. 2014;15:170-180. doi:10.1038/nrn3666 


\section{Publish your work in this journal}

The Journal of Pain Research is an international, peer reviewed, open access, online journal that welcomes laboratory and clinical findings in the fields of pain research and the prevention and management of pain. Original research, reviews, symposium reports, hypothesis formation and commentaries are all considered for publication. The manuscript

Submit your manuscript here: https://www.dovepress.com/journal-of-pain-research-journa management system is completely online and includes a very quick and fair peer-review system, which is all easy to use. Visit http:// www.dovepress.com/testimonials.php to read real quotes from published authors. 